\title{
Article \\ Quantification of Doughnut Economy with the Sustainability Window Method: Analysis of Development in Thailand
}

\author{
Jyrki Luukkanen*(D), Jarmo Vehmas and Jari Kaivo-oja \\ Finland Futures Research Centre, University of Turku, FI-20014 Turku, Finland; jarmo.vehmas@utu.fi (J.V.); \\ jari.kaivo-oja@utu.fi (J.K.-o.) \\ * Correspondence: Jyrki.luukkanen@utu.fi; Tel.: +358-50-3370710
}

Citation: Luukkanen, J.; Vehmas, J.; Kaivo-oja, J. Quantification of Doughnut Economy with the Sustainability Window Method: Analysis of Development in Thailand. Sustainability 2021, 13, 847. https:// doi.org/10.3390/su13020847

Received: 17 December 2020 Accepted: 14 January 2021 Published: 16 January 2021

Publisher's Note: MDPI stays neutral with regard to jurisdictional clai$\mathrm{ms}$ in published maps and institutional affiliations.

Copyright: (C) 2021 by the authors. Licensee MDPI, Basel, Switzerland. This article is an open access article distributed under the terms and conditions of the Creative Commons Attribution (CC BY) license (https:// creativecommons.org/licenses/by/ $4.0 /)$.

\begin{abstract}
The doughnut economy is a new approach for the inclusion of planetary boundaries and social foundation in the development of societies. The Sustainable Development Goals of the United Nations (UN) determine another view for development targets. The developed sustainability window approach provides a means for operationalization and quantification of the doughnut economy. The developed method calculates minimum economic development to guarantee sustainable social development and maximum economic development not to exceed environmental sustainability. The developed method, advanced suitability analysis (ASA) doughnut, is illustrated with case data from Thailand. The sustainability doughnut for Thailand has been calculated for both weak and strong sustainability criteria. It seems that strong sustainability is a too strict requirement regarding several environmental dimensions of development while the weak sustainability criteria are fulfilled. The developed method and tool are flexible and can be used for comparative analysis of different countries or regions, for dynamic analysis of sustainability development, for gap analysis of the required improvement of environmental or social efficiency, and analysis of degrowth possibilities. The selection of indicators for the analyses and their reliability is crucial for the validity of the results and usefulness in policy planning.
\end{abstract}

Keywords: sustainability; advanced sustainability analysis (ASA); Sustainable Development Goals (SDGs); indicators; demonstration study; doughnut economy; sustainability window; Thailand

\section{Introduction}

More than 30 years ago, the report of the World Commission on Environment and Development (WCED) [1] introduced a catchword of sustainable development and its environmental, social, and economic dimension. The report highlighted the need to ensure ecological sustainability, satisfying basic human needs and equity in the long term. Since then, the idea of sustainable development as a policy goal has been globally shared by different countries, organizations, companies, and other economic actors. Increasing attention has been paid to the environmental and social challenges related to different economic activities. The WCED report has also affected the discussion on development indicators, and especially the common practice to use gross domestic product (GDP) as a macro-level indicator of welfare has been criticized because it only includes the economic dimension and ignores other aspects impacting welfare.

In most countries all over the world, the trend of conventional GDP has been continuously increasing except during some relatively short periods of economic recessions (in the 1930s and 1990s, and the financial crisis in 2008-2009) and external crises such as the World War II, oil shocks in the 1970s, and the COVID-19 pandemic in the 2020s. After the publication of the WCED report, several attempts to replace the conventional GDP with a better indicator have been made. New monetary indicators-some of them originally initiated even earlier-such as Green GDP [2-4], Indicator of Sustainable Economic Welfare (ISEW) [5,6], and Genuine Progress Indicator (GPI) [7,8] were introduced in the field of 
environmental economics. The alternative monetary indicators ISEW and GPI tended to show a decreasing trend in many countries after a peak around the year 1980 [9].

Sustainable development indices covering factors other than the economic dimension of sustainability have also been developed [10], such as Human Development Index (HDI) [11,12], ecological footprint [13,14], and Sustainable Society Index (SSI) [15], for instance. Empirical analyses using these kinds of indices often show that the performance of countries is far from sustainable [16]. Attempts to solve global development problems by new "beyond GDP" welfare indices have also been criticized because moving beyond GDP requires good reflexivity, i.e., awareness of the key role that pre-analytical choices play in the definition of welfare and how to measure welfare [17].

Neither the alternative monetary indicators nor the sustainable development indices have been able to make a serious political breakthrough, and the administrative and statistical practices have not been changed much. GDP has kept its dominant position. In the meantime, the idea of developing sustainable development indicator sets (SDIs) describing all dimensions of sustainability in detail was put forward in organizations such as the United Nations [18], Organization of Economic Co-operation and Development [19], and the European Union [20]. At the national level, especially ministries and administrative units responsible for environmental issues and sustainability have developed their own SDIs. For example, in Finland, quite a broad group of stakeholders was involved in the process of developing a national SDI set, with a purpose to include all aspects considered as relevant for sustainability [21]. Moreover, elsewhere the result has often been quite a large number of individual indicators. The United Nations (UN) has developed indicators concerning the 17 Sustainable Development Goals (SDGs) launched in 2015 [22]. The SDGs have been adopted in the EU [20] and other countries following the UN 2030 Agenda for Sustainable Development, and they have influenced the work on SDIs. However, the major problem of SDIs seems to remain as years go passing by-GDP still dominates the use of performance indicators at the national level and in international comparisons. The use of the SDIs has not been what was expected [21].

The global indicator framework for Sustainable Development Goals was developed by the Inter-Agency and Expert Group on SDG Indicators (IAEG-SDGs) and agreed upon at the 48th session of the United Nations Statistical Commission held in March 2017 (SDG indicators). The indicator set related to the Sustainable Development Goals consists of 169 targets for the 17 goals and 231 unique indicators.

Raworth $[23,24]$ introduced a visual representation of sustainable development called doughnut economy. Domazet et al. [25] call the doughnut economy a mental model of sustainability. The idea of this article is to operationalize the mental model of the doughnut economy and provide a mathematical method to quantify it. The "doughnut" represents the available space for economic growth between a lower and upper limit, i.e., between the social foundation and the environmental ceiling (Figure 1). The social foundation refers to the minimum GDP necessary to satisfy the basic human needs, and the carrying capacity of nature sets the environmental ceiling which refers to the maximum GDP allowed by the environmental constraints. In between, there is a safe and just space for humanity which allows inclusive and sustainable economic development (Figure 1).

Raworth [23] refers to Rockström et al. [26] when she includes climate change, freshwater use, nitrogen and phosphorous cycles, ocean acidification, chemical pollution, ozone depletion, biodiversity loss, and land-use change in the description of the environmental ceiling. These environmental issues can be used to define natural thresholds of environmental sustainability. The social foundation includes critical human deprivations such as income, education, resilience, voice, jobs, energy, social equity, gender equality, health, food, and water $[23,24,26]$. The doughnut economy includes nothing new, but it summarizes and visualizes many elements of the environmental and development discussion during the last decades. Therefore, the doughnut economy is also prone to all contemporary and prevailing criticisms of sustainable development. 


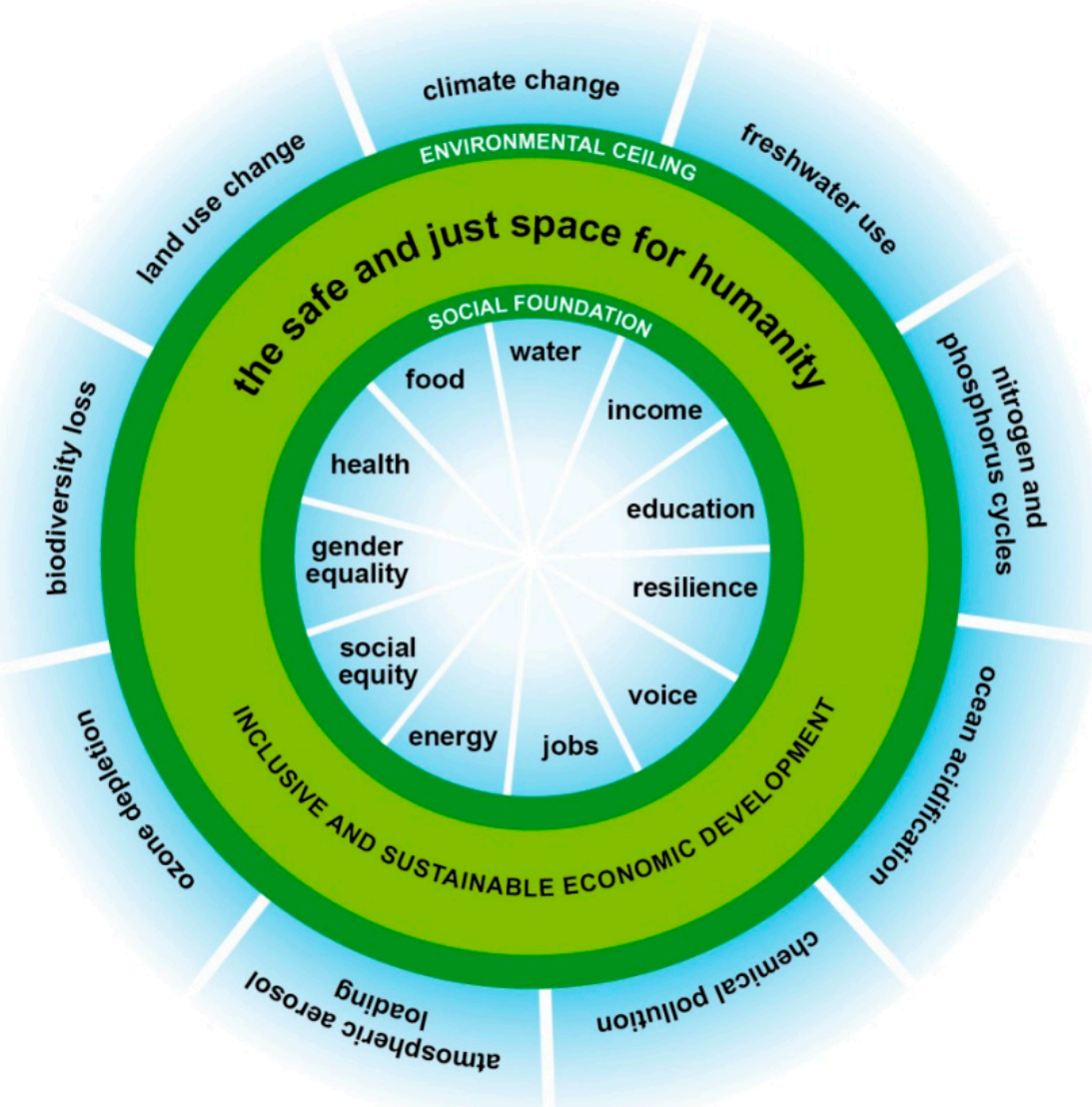

Figure 1. The doughnut economy [23].

The economic development concerning both the environmental ceiling and social foundation can be empirically analyzed by using the available indicator data. Comparison of different countries is interesting, but a suitable dataset for this is a challenge because the countries are very different from each other. The SDG indicator data offers a good starting point for this. If a time series of data is available, it is possible to assess whether the economic activity of a country or other regional entity "fits in the doughnut" or not and if it is developing towards sustainability or away from it. In addition to the definition of the absolute level of sustainability, the direction of change is a crucial element of sustainability assessment.

Sustainability assessment can be done (1) at various spatial and geographical levels from local to global, (2) for the whole economy or a part of it, i.e., the different economic sectors, or selected practices/technologies (such as energy sources and technologies, industrial branches, transport modes, crops and livestock, households, (3) for individual companies, organizations, etc., and (4) by focusing on different sustainability dimensions, either separately or integrated. Environmental sustainability dominates the assessment and environmental impact assessment and environmental reporting that has been institutionalized in many countries. However, the integrated assessment has become more popular in recent years. A large variety of methods with manifold empirical applications are available in the large literature.

The doughnut economy wraps up many earlier ideas on problems in the developed and developing countries such as the limits to growth [27], the three dimensions of sustainability [1], the steady-state economy [28], the SDGs [22], and the ideas included in various sustainability indices and SDI sets. One important area of research is the interaction between different SDGs. There have been theoretical analyses of the interactions [29] but very little quantitative empirical research even though some analyses of the synergies have been carried out [30]. In the literature, the doughnut economy is not widely referred to, 
and no explicit operationalization with an empirical example is available although the idea was first published in 2012.

In this article, the first attempt to operationalize the doughnut economy will be made by using the economy of Thailand as an example. A set of selected SDIs describing the different dimensions of sustainability and the SDGs will be used in the empirical analysis based on the sustainability window method, which will be presented in the next section including also a description of the data used in the analysis of Thailand. Sustainability window defines the minimum economic development level to fulfil the criteria of social sustainability and the maximum economic development not to exceed the environmental sustainability limit. The research question is how to quantitatively operationalize the doughnut economy based on the sustainability window approach. Results from the empirical analysis will be presented in Section 3. Section 4 deals with the development needs and ideas for further research, and draws conclusions.

\section{Materials and Methods}

Sustainability window analysis is based on the advanced sustainability analysis (ASA) approach. The ASA approach was developed in Finland Futures Research Centre [31-33] providing a general framework for analyzing sustainability. The approach deals with changes in development, not absolute values, because in most cases it is not possible to define whether the environmental or social state is sustainable or not on an absolute scale. There is, for instance, no absolute level of emissions, which can be seen as sustainable. The ASA approach defines whether the development is towards a more sustainable or a less sustainable direction.

The ASA approach can be used for the identification, quantification, and analysis of dematerialization, immaterialization, and the rebound effect [34]. Dematerialization relates to the production side of the economy and is measured with the material intensity of production. Decreasing the material intensity of production over time indicates dematerialization - the same amount of value added is produced with less use of material (and with less related environmental impacts). If the material intensity of production increases, it is called re-materialization. Change in dematerialization depends on, e.g., change of activity in the economic sectors with different material intensities, and how well technological development focuses on "green" technologies or otherwise applies to the use of materials.

Immaterialization deals with the consumption side of the economy and is measured with the material intensity of consumption. The decreasing material intensity of consumption indicates immaterialization-the same consumer needs are satisfied with less use of material. If the material intensity of consumption increases, it is called re-materialization. Change in immaterialization depends on many things, such as consumer preferences and behavior, and the availability of different alternatives, i.e., products, services, and ways to use them, to satisfy different human needs.

Both dematerialization of production and immaterialization of consumption are important for a transition towards policy goals such as sustainable development, circular economy, and climate change mitigation and adaptation. However, observations of dematerialization or immaterialization do not necessarily ensure that the total use of natural resources has decreased. If economic growth is faster than dematerialization or immaterialization, its increasing effect can override the decreasing effects of dematerialization and immaterialization on the total use of natural resources. In the ASA approach, the effect of economic growth is called the gross rebound effect. If the gross rebound effect exceeds the effect of dematerialization or immaterialization, the total use of material resources and related environmental impact still increases.

In regard to global climate change, the strong criterion for the environmental sustainability would be that the greenhouse gas emissions should not grow (see discussion on strong sustainability in Vehmas et al. [35] and Kaivo-oja et al. [36]). In terms of ASA, this means that the decreasing effect of dematerialization to greenhouse gas (GHG) emissions 
is larger than the gross rebound effect of economic growth. This is, in practice, a too strong criterion for example for a country like Cambodia, where the $\mathrm{CO}_{2}$ emissions per capita have been 0.2 ton of $\mathrm{CO}_{2 \mathrm{eq}}$ in the reference year (2006) of this analysis (global average being about 4 tons of $\mathrm{CO}_{2 \mathrm{eq}}$ ). That is why we utilize in this analysis also the weak sustainability criterion for the $\mathrm{CO}_{2}$ emissions, which states that the emissions per produced GDP should not increase. Weak sustainability criterion generally means that the environmental indicator in relation to economic development, i.e., environmental intensity (environmental indicator/GDP), should not increase.

The sustainability window (SuWi) method [37-39] provides quantitative information about the maximum economic development to avoid negative change in the environmental condition (related to a selected environmental indicator) and the minimum economic development to achieve positive social development (related to a selected social indicator). These maximum and minimum levels of economic development define the sustainability window.

In the analyses, we use GDP as an indicator for the economic activity. There have been a lot of critics of using GDP as an indicator because it includes only economic aspects and no other welfare aspects. This is, however, what is needed in the sustainability window and ASA doughnut analysis. The idea is to have other aspects, like unemployment, poverty, etc., included in the social dimension of sustainability. The idea is to analyze, for instance, what the unemployment productivity of GDP is and calculate the minimum level of GDP development so that unemployment does not increase (lower boundary for sustainability). This determines the social foundation referring to the minimum GDP necessary to satisfy the basic human needs. The approach that we have used is thus relying on the Raworthian Doughnut economy approach for determining the minimum level of economic development in order to fulfil the social sustainability criteria.

A basic case for determining the maximum economic development in relation to environmental stress is shown in Figure 2. The indicators for economic development and environmental stress are indexed to have the value 1 in the base year indicated with point $A$ in the figure having values $\mathrm{GDP}_{0}$ and $\mathrm{Env}_{0}$. This point determines the environmental stress productivity of GDP with line r1. The final point of development is indicated with point $B$ having values $\mathrm{GDP}_{1}$ and $\mathrm{Env}_{1}$. At this point, the environmental stress productivity of GDP is expressed with line r2. The criterion for environmental sustainability is that environmental stress should not increase. With the environmental stress productivity $\mathrm{r}$, the maximum sustainable economic development is indicated with point $C$ having a value GDP $_{\max }$. The increase in environmental stress and GDP with decreased environmental stress productivity allows smaller GDP growth than the original growth not to increase the environmental stress from the base year level.

A basic case for determining the minimum economic development in relation to social welfare development is shown in Figure 3. The indicators for economic development and social welfare in the base year are indicated with point $\mathrm{A}$ in the figure having values $\mathrm{GDP}_{0}$ and $\mathrm{Soc}_{0}$. This point determines the social welfare productivity of GDP with line r1. The final point of development is indicated with point $B$ having values $\mathrm{GDP}_{1}$ and $\mathrm{Soc}_{1}$. At this point, the social welfare productivity of GDP is expressed with line $\mathrm{r} 2$. The criterion for social sustainability is that social welfare should not decrease. With the social development productivity $\mathrm{r} 2$, minimum sustainable economic development is indicated with point $C$ having a value $\mathrm{GDP}_{\min }$. The increase in welfare with the decrease in welfare productivity defines a minimum GDP value higher than the base year value not to decrease the social welfare. 


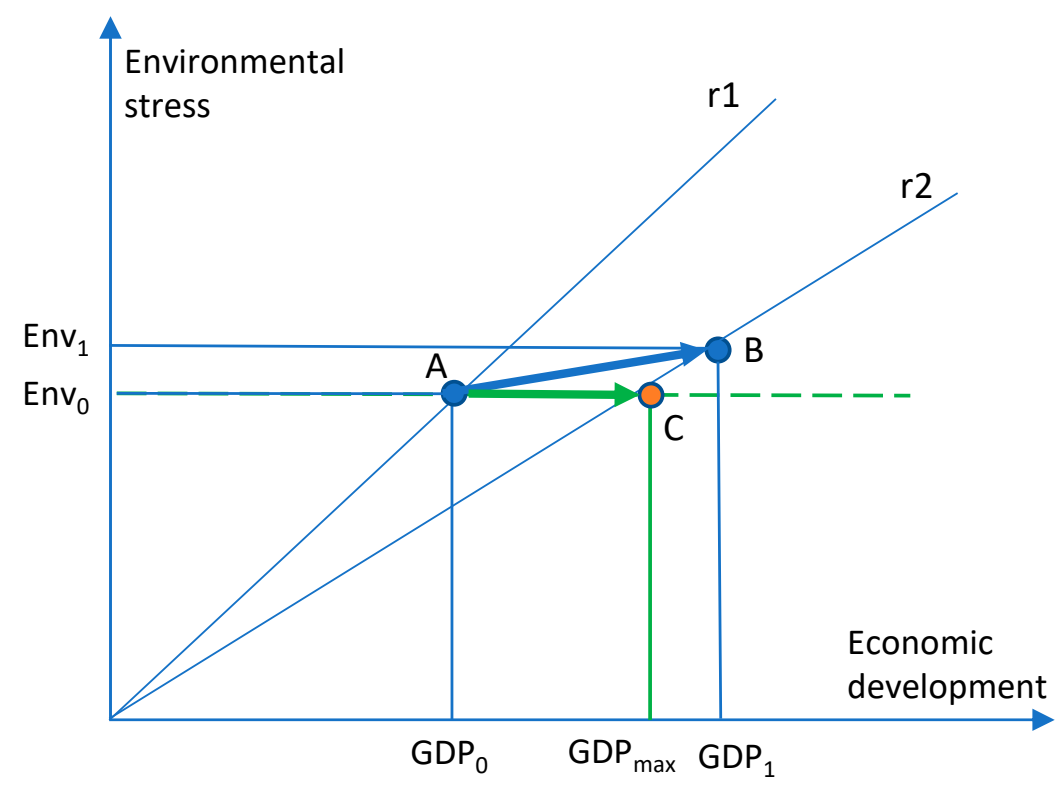

Figure 2. Determining the maximum economic growth related to environmental stress production.

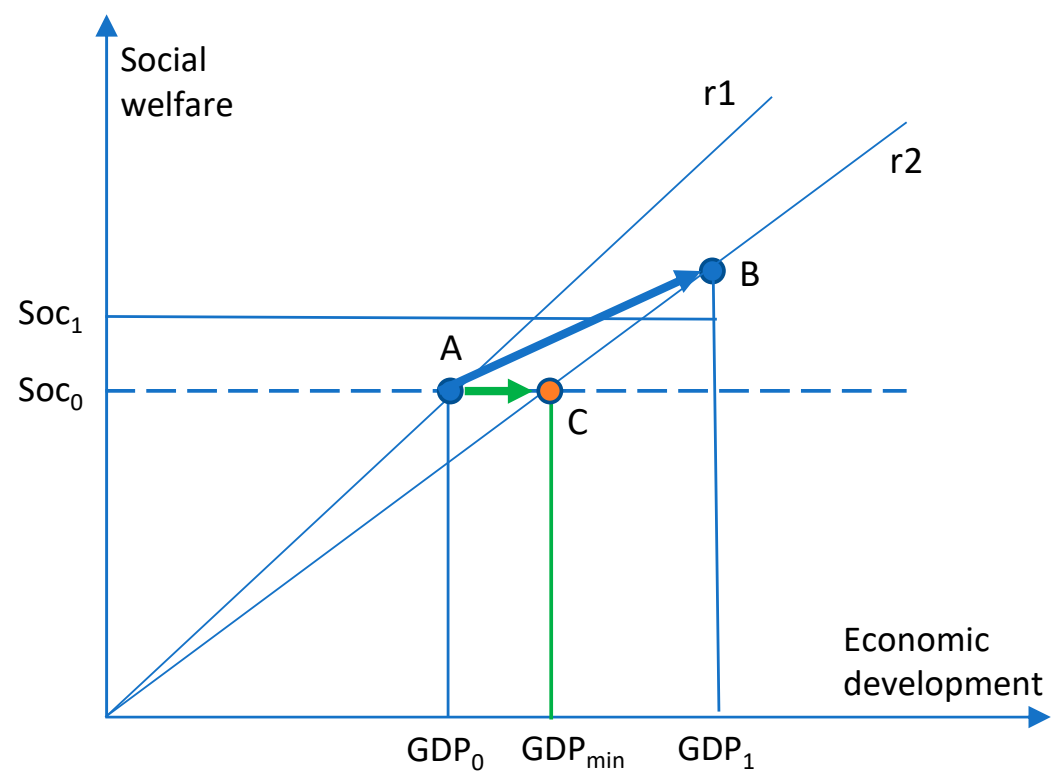

Figure 3. Determining the minimum economic development not to decrease social welfare.

When the cases of environmental and social sustainability are combined, we can determine the sustainability window with the minimum and maximum economic development. This is shown in Figure 4. The maximum sustainable economic development GDP $\max$ is defined with the productivity line $\mathrm{r} 2$ (point $\mathrm{D}$ ) and the minimum sustainable economic development $\mathrm{GDP}_{\min }$ is defined with the productivity line r3 (point $\mathrm{E}$ ). In this case, the real GDP growth is too high $\left(\mathrm{GDP}_{1}\right.$ is higher than $\left.\mathrm{GDP}_{\max }\right)$ and the sustainability criteria are not satisfied. 


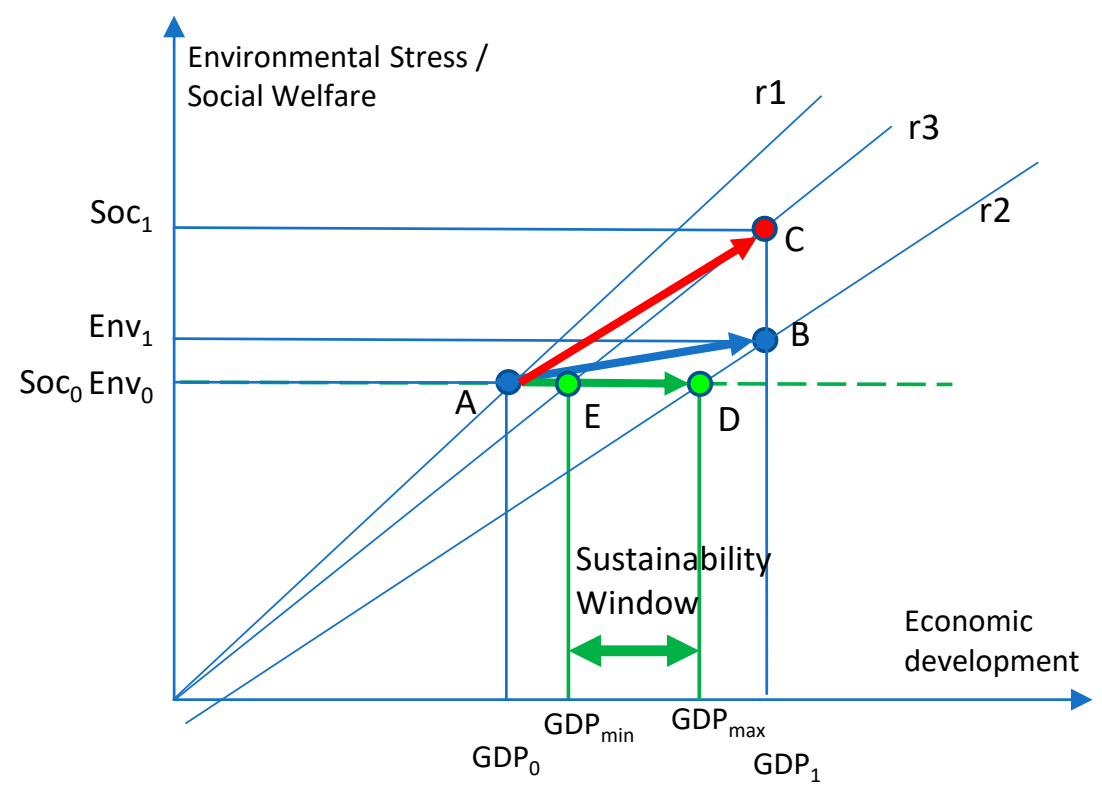

Figure 4. Determining the sustainability window (SuWi) with the minimum (GDP $\left.{ }_{\min }\right)$ and maximum $\left(\mathrm{GDP}_{\max }\right)$ economic development.

The data sources for the calculation of the ASA doughnut were:

- $\quad$ Sustainable Society Index (SSI) data for most of the indicators [15,40]

- International Energy Agency (IEA) for the energy and $\mathrm{CO}_{2}$ emission data [41]

- $\quad$ United Nation's Development Programme (UNDP) for the Human Development Index (HDI) data [42]

The SSI index series have bi-annual data for the time period of 2006-2016. However, the data for the year 2016 seems not to be compatible with all indicators with the previous data. That is why we used only data for the year 2006 as the base year and 2014 as the final year of comparison in the analysis. For more details of the indicators, see (SSI) [40].

For the illustrative ASA doughnut analysis, we used indicators shown in Table 1, for which considerably reliable data was available. The indicators had to be modified so that all the social indicators increased with increasing welfare and all the environmental indicators increased with increasing environmental stress. For instance, "Sufficient food" was calculated to be $100 \%$-Undernourished(\%).

Table 1. Indicators used for the sustainability window and ASA doughnut analysis. For the Sustainable Society Index (SSI) indicators see SSI [33].

\begin{tabular}{|c|c|c|c|c|}
\hline \multicolumn{2}{|c|}{ Social Indicator } & \multicolumn{2}{|c|}{ Environmental Indicator } & Economic Indicator \\
\hline S1 & Sufficient Food & & $\begin{array}{l}\text { Biodiversity, } \\
\text { forest area }\end{array}$ & GDP \\
\hline S2 & Sufficient to Drink & $\mathrm{E} 4$ & $\begin{array}{c}\text { Consumption of } \\
\text { global hectares }\end{array}$ & \\
\hline S3 & Education & E5 & Energy Intensity & \\
\hline S4 & Healthy Life & E7 & $\begin{array}{l}\text { Greenhouse } \\
\text { Gases }\end{array}$ & \\
\hline S5 & Gender Equality & E8 & $\begin{array}{c}\text { Renewable } \\
\text { Energy }\end{array}$ & \\
\hline S6 & Income Distribution & E9 & Organic Farming & \\
\hline S8 & Employment & E10 & $\begin{array}{c}\text { Unsafe } \\
\text { Sanitation }\end{array}$ & \\
\hline S10 & $\begin{array}{l}\text { Human Development } \\
\text { Index HDI }\end{array}$ & & & \\
\hline
\end{tabular}


Sustainability window analyses have so far been carried out for China [38], Lao PDR [39], and Indonesia [43,44].

In this article, we illustrate the sustainability window cases with examples from Thailand. We have used Thailand as a case study because the data availability and reliability is quite good. Thailand is an example of a fast-growing newly industrialized developing country which is still relying considerably on agricultural production $(31 \%$ of the workforce and $8 \%$ of GDP [45]) but has a modern industrial sector $(17 \%$ of the workforce in manufacturing and $6 \%$ in construction, and $28 \%$ of GDP [45]) and an important service sector ( $42 \%$ of the workforce and $58 \%$ of GDP [45]).

Thailand has the 8th largest economy in Asia, but now has growth restrained largely by slowing exports; Thailand posted growth at $2.4 \%$ in 2019 . GDP growth is likely to slow further to $-4.8 \%$ in 2020 but could pick up to $2.5 \%$ in 2021 . COVID-19 could have a large impact on future growth prospects because Thai economy is heavily dependent on international trade and tourism [46].

We have to remember that in Thailand, the GDP does not describe the total economic activity because the share of shadow economy is quite high. It has been estimated that in 2004, the share of shadow economy was about $40 \%$ of the economic activities [47]. In the SuWi analysis, we refer to the changes in the GDP and other indicators and if we assume that the share of shadow economy has not changed considerably during the research period, it does not affect the results.

Thailand belongs to the ASEAN countries (The Association of Southeast Asian Nations) and is also a member of the largest trade area of RCEP (the Regional Comprehensive Economic Partnership) having prospects of considerable future economic growth.

For the construction of the example sustainability window for Thailand (Figure 5), we used "consumption of global hectares" as the environmental indicator and "Healthy life years" as the social indicator. Point A in the figure indicates the base year value for social, environmental and economic indicators. Point $B$ indicates the final year value of the social indicator "healthy life years" and the line r2 indicates the social welfare productivity in the final year. The social sustainability criterion is that social welfare should not decrease, and point $\mathrm{D}$ indicates the minimum economic development $\left(\mathrm{GDP}_{\min }\right)$ to fulfil the criterion with the welfare productivity of $\mathrm{r} 2$.

Point $C$ indicates the final year value for the environmental indicator "Consumption of global hectares" and line r3 indicates the environmental stress productivity of GDP in the final year. The environmental sustainability criterion is that environmental stress should not increase, and point $\mathrm{E}$ indicates the maximum economic development (GDP $\max$ ) to fulfil the criterion with the environmental stress productivity of $r 3$. In this case, the real economic development GDP real $_{\text {is higher than }} \mathrm{GDP}_{\min }$ and lower than GDP $\max$ fulfilling both social and environmental sustainability criteria when these indicators are used.

In Figure 6, we illustrate the strong and weak sustainability window for Thailand using "food sufficiency" as the social indicator and "consumption of global hectares" as the environmental indicator. Point A illustrates the base year values for all the indicators and line $\mathrm{r} 1$ indicates the related productivities. Point B indicates the final year value for "food sufficiency" and line $\mathrm{r} 2$ indicates the related welfare productivity. The social sustainability criterion is that the social welfare should not decrease and in this case point $\mathrm{E}$ determines the minimum economic development $\left(\mathrm{GDP}_{\min }\right)$ to fulfil the criterion. In this case, $\mathrm{GDP}_{\min }$ is smaller than the base year value indicating a possibility for degrowth without decreasing social welfare. 


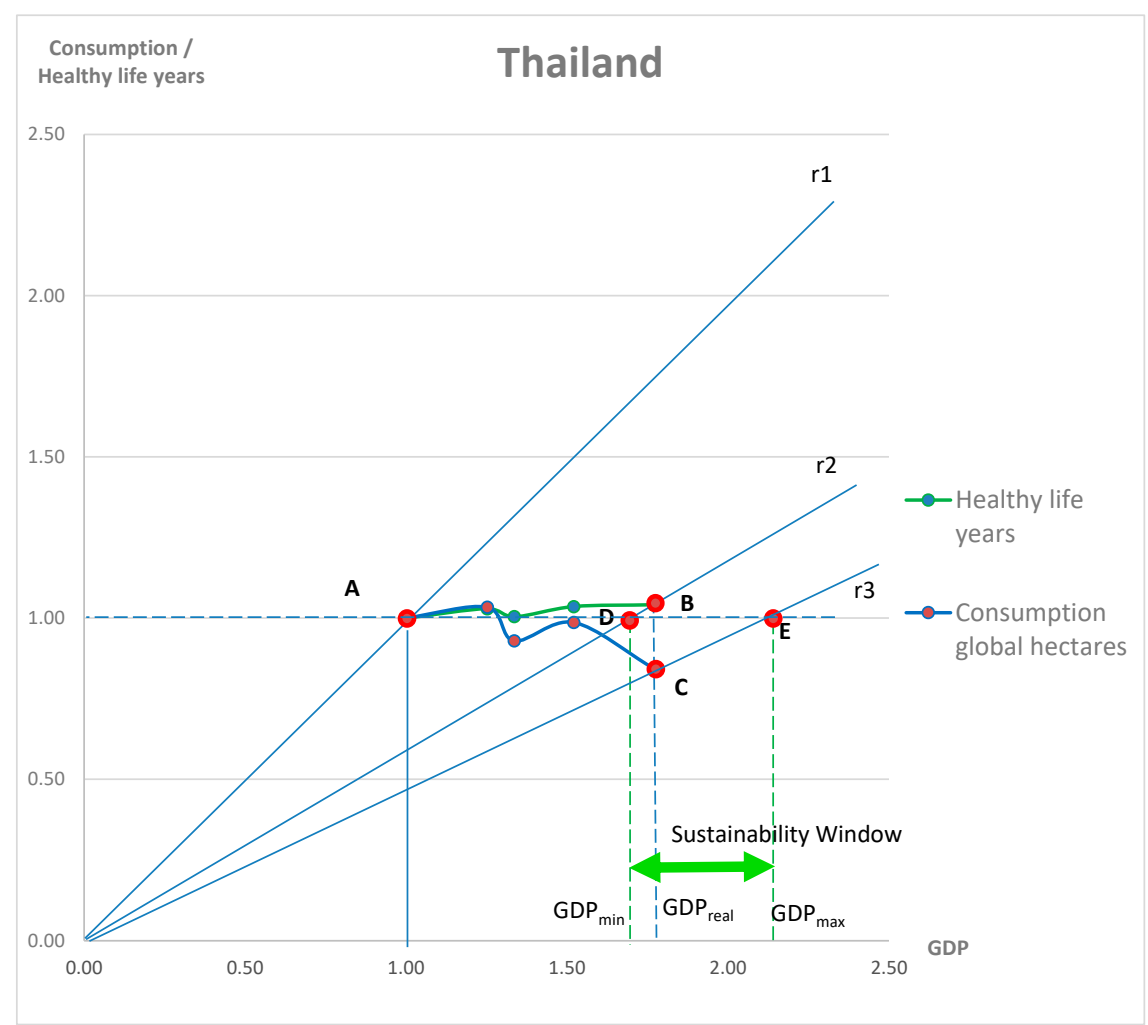

Figure 5. Determining the sustainability window for Thailand using "consumption of global hectares" as the environmental indicator, "healthy life years" as the social indicator, and gross domestic product (GDP) as the economic indicator.

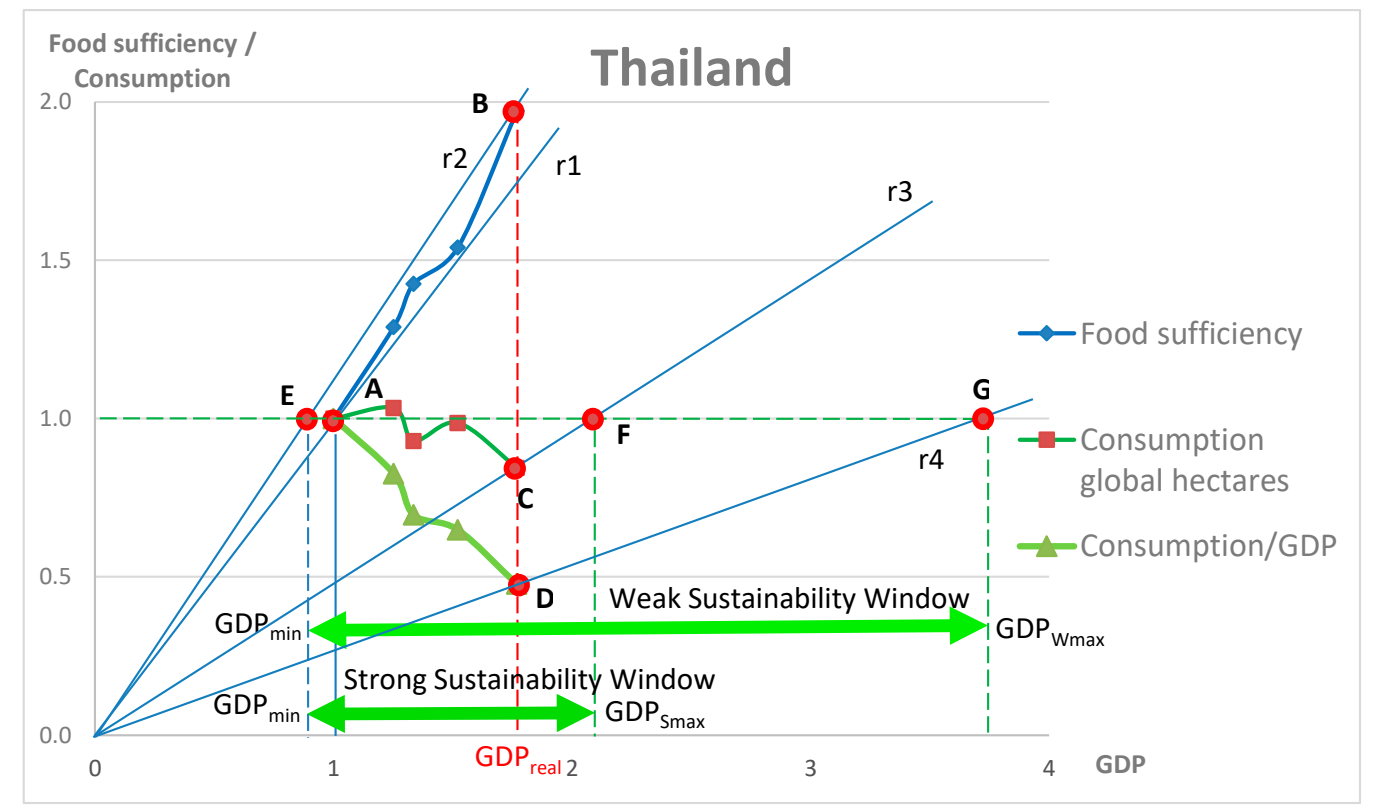

Figure 6. Determining the sustainability window for Thailand using "consumption of global hectares" as the strong environmental indicator, "consumption of global hectares/GDP" as the weak environmental indicator, "healthy life years" as the social indicator, and GDP as the economic indicator.

Point $C$ in the figure illustrates the final year value for the environmental indicator "consumption of global hectares" and line r3 illustrates the related environmental stress productivity. In this case, point $\mathrm{F}$ determines the maximum economic development $\left(\mathrm{GDP}_{\mathrm{Smax}}\right)$ not to increase environmental stress. In this case, the value refers to the strong sustainabil- 
ity criterion, which requires that the absolute value of the environmental stress indicator should not increase. $\mathrm{GDP}_{\min }$ and $\mathrm{GDP}_{\text {Smax }}$ determine the strong sustainability window.

When we use the weak criterion for environmental sustainability, we use the indicator "consumption of global hectares/GDP", with point D and line r4 illustrating the related environmental stress productivity. The maximum economic development related to weak sustainability $\left(\mathrm{GDP}_{\text {Wmax }}\right)$ is determined by point $\mathrm{G}$. Using these indicators, the real GDP growth $\left(\mathrm{GDP}_{\text {real }}\right)$ fulfils both the strong and weak sustainability criteria.

Figure 7 illustrates a case where we will have a negative sustainability window and related efficiency gap in development. In this case, we use "healthy life years" as the social indicator and "greenhouse gas emissions" as the environmental indicator referring to strong sustainability criterion. The base year values for the indicators are illustrated by point A. Point $B$ illustrates the final year value for social indicator and line $r 2$ illustrates the related welfare productivity. Point $\mathrm{D}$ determines the minimum economic development $\left(\mathrm{GDP}_{\min }\right)$ not to decrease social welfare. Point $C$ illustrates the final year value for the environmental indicator and line $\mathrm{r} 3$ the related environmental stress productivity. The maximum economic development $\left(\mathrm{GDP}_{\max }\right)$ is now determined by point $\mathrm{E}$. In this case, we notice that the maximum economic development is smaller than the required minimum development resulting in a negative sustainability window. In order to reach sustainability, the efficiency gap in environmental development should be fulfilled by reducing the environmental stress productivity to the value illustrated by line $\mathrm{r} 4$. In such a case, we would have a positive sustainability window $\left(\mathrm{SuWi}_{\text {eff }}\right)$ with the maximum economic development (GDP $\operatorname{maxE}_{\text {E }}$ ) equaling the real GDP growth. This example shows that the presented analytical framework can be used also for the efficiency gap analysis. The efficiency gap analysis can also be used for analyzing whether social welfare productivity is high enough for social sustainability.

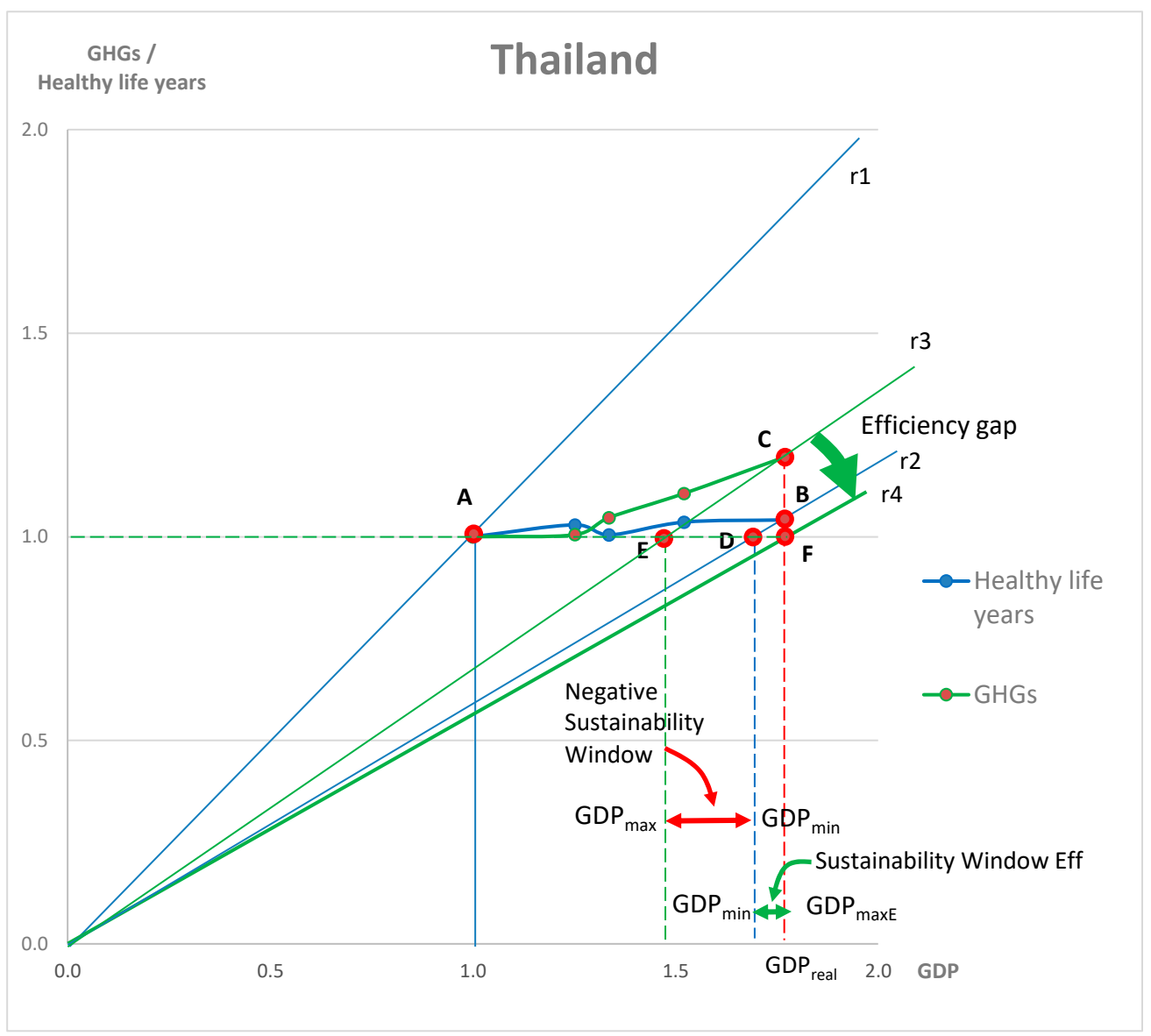

Figure 7. Determining sustainability window in a case where it becomes negative and illustrating the related efficiency gap. 
The use of strong and weak sustainability in the SuWi analysis provides a means for equitable analysis of development in developing countries. In many cases, the requirements of strong sustainability are too pronounced for developing countries with, for instance, a very low level of greenhouse gas emissions. In these cases, the use of weak sustainability criteria can be justifiable.

\section{Results}

The SuWi analysis produces results of the pairwise comparison of different social and environmental indicators in relation to economic development. When these pairwise minimum and maximum economic development results are organized in a radial diagram, we get as a result a doughnut diagram, ASA doughnut, for sustainable development. The minimum economic development determines the inner circle of the doughnut and the maximum defines the outer circle provided that the minimum is smaller than the maximum. The illustrated ASA doughnut can be compared to the actual economic development in the radial diagram.

This novel approach to utilize sustainability window results for construction of ASA sustainability doughnut provides a way to visually compare the development in different dimensions of sustainability. This is a scientific breakthrough for the quantification of the Raworthian doughnut economy and gives a comprehensive view of the problematic and successful development areas.

For the doughnut construction for Thailand, we selected different social and environmental indicators as a case study. The selection of the indicators was based on the idea that they should provide a view of the different aspects of social and environmental development and be reliable enough for the analysis. The list of the selected indicators is shown in Table 1 in Section 2.

The ASA doughnut figure for Thailand concerning weak sustainability for 2006-2014 is shown in Figure 8. In the figure, the blue line indicates the maximum GDP growth so that the environmental stress (measured with weak sustainability) does not increase. The green line indicates the minimum GDP growth in order to safeguard social sustainability. The area between the minimum and maximum GDP development is shown as a green doughnut, i.e., the area for weak sustainability. The red line indicates the index for real GDP change. If the red line is on the green background doughnut, the actual development can be evaluated to be sustainable in relation to the indicators.

The ASA doughnut shows that the development in Thailand has fulfilled the weak environmental sustainability criteria for biodiversity (forest area), consumption of global hectares, energy intensity, $\mathrm{CO}_{2}$ emissions, renewable energy use, and safe sanitation. The problem area seems to be organic farming.

The minimum criteria for sustainable social development are fulfilled in the areas analyzed with these indicators. This means that the real GDP growth has been larger than the minimum socially sustainable growth. This can be seen in the figure where the green line is inside the red circle, which represents the real GDP growth.

The ASA doughnut for the strong sustainability analysis is shown in Figure 9. The requirement for strong environmental sustainability (environmental stress should not increase) seems to be too demanding for Thailand for most of the selected indicators.

The strong environmental sustainability criteria are fulfilled in Thailand in "consumption of global hectares" (E4), and slightly in "biodiversity, forest area" (E1) and "energy intensity" (E5). For all the other indicators, the criteria for strong environmental sustainability are not fulfilled. The social sustainability is, however, achieved regarding all the selected indicators as was explained in the case of weak sustainability. 


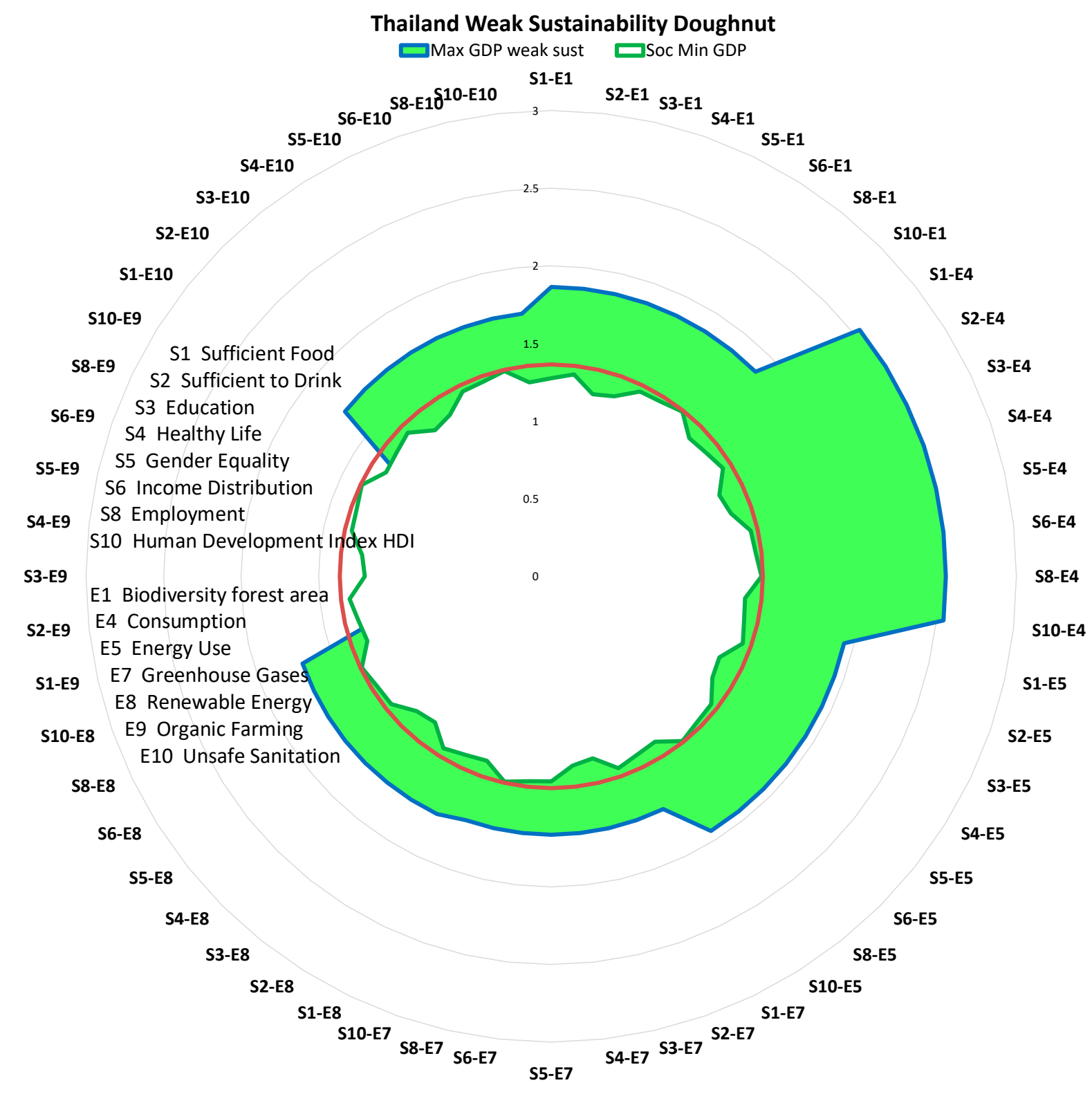

Figure 8. Weak sustainability advanced suitability analysis (ASA) doughnut for Thailand for the change between $2006-2014$. The blue line indicates the maximum GDP growth in relation to environmental sustainability and the green line indicates the minimum GDP growth in relation to social sustainability. The red line indicates the index for real GDP change. If the red line is on the green background Doughnut the development can be evaluated to be sustainable in relation to the indicators. The codes for environmental and social indicators are presented in Table 1. 


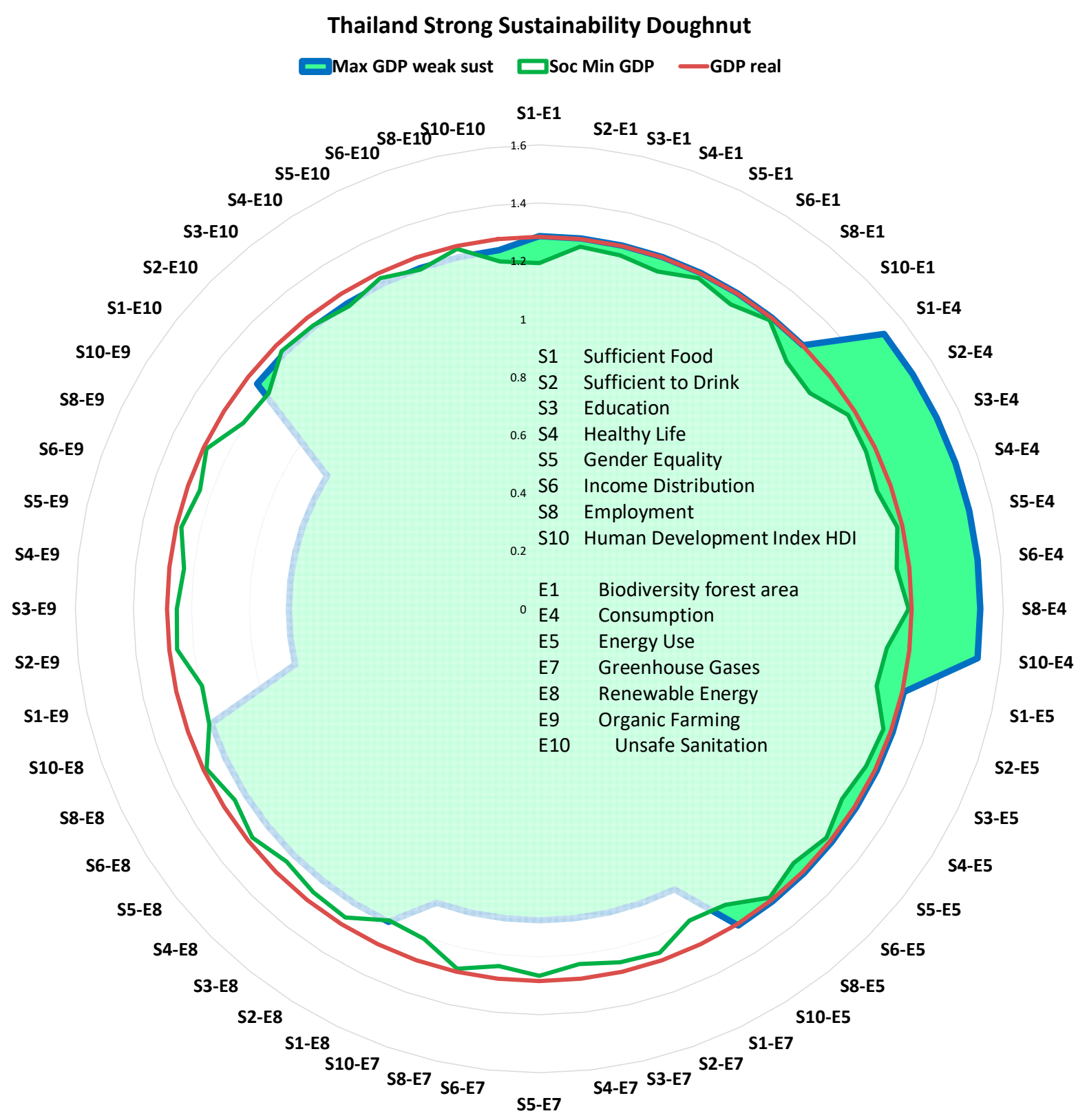

Figure 9. The strong sustainability ASA doughnut for Thailand for the change between 2006-2014. The blue line indicates the maximum GDP growth in relation to strong environmental sustainability and the green line indicates the minimum GDP growth in relation to social sustainability. The red line indicates the index for real GDP change. If the red line is on the darker green background doughnut, the development can be evaluated to be sustainable in relation to the indicators. The codes for environmental and social indicators are presented in Table 1.

\section{Discussion and Conclusions}

The sustainability window (SuWi) approach provides a new means for quantifying the doughnut economy analysis. The developed methodology is general in nature and can be used for any country or province or group of countries when suitable quantitative indicators are available. With the SuWi approach, it is possible to calculate the sustainable environmental ceiling for development as well as sustainable social foundations using available indicators. This can form a basis for assessing the past development and planning future policies. The significance of the new method is that we can carry out a simultaneous quantitative analysis of different dimensions of sustainability in order to provide a com- 
prehensive view of the development process. It provides a practical tool for utilizing the indicator sets of sustainable development and assessing the development process towards the Sustainable Development Goals utilizing the involved gap analysis.

The SuWi approach can be used for gap analysis, identifying the need for improvements in the performance in different areas of development [30]. The gap analysis reveals the lack of development in the efficiency of environmental stress productivity of GDP. With the gap analysis, we can determine how much more efficient, in an environmental sense, the economic development should be in relation to different environmental stress factors. In addition, the SuWi approach can be used for analyzing the gap in social welfare productivity. The analysis reveals in which area of social development the need to increase social productivity is most urgent in order to reach social sustainability.

The sustainability window (SuWi) approach and the ASA doughnut model provide possibilities for analyzing the dynamics of sustainable development [36]. The SuWi approach can be used for trend analysis of the different components of sustainability. It can form a basis for scenario building when different interactions of the components are analyzed in the comprehensive framework and the future options are systematically evaluated. The dynamic doughnut model can provide an overview of the development in different spheres and give valuable information for policy planning about the areas where special policy interventions are needed.

Analysis of degrowth is a possible option using the SuWi and doughnut analysis approach. Sustainable degrowth requires that the intensity development of social welfare production is positive. This means that the change in "social indicator"/GDP is positive, which makes it possible to have a decrease in GDP without decreasing social welfare. This indicates that socially sustainable development is possible in the case of negative GDP growth, but it requires improvement in the social welfare productivity of GDP. The $\mathrm{SuWi}$ /doughnut model provides a tool for analyzing possible areas where degrowth is a sustainable option.

The Thailand case analysis shows that the quantitative construction of the view of doughnut economy is possible using the SuWi approach. The case study indicates the difference between the weak and strong sustainability approach. Development in Thailand shows positive change in most measured areas when we use weak sustainability criteria, but the strong sustainability criteria seem to be too demanding regarding most indicators. For developing countries, the strong sustainability requirement is too hard for most indicators because the base year level of environmental emissions or energy use or similar indicators is very low in most cases. If, for instance, the emissions of $\mathrm{CO}_{2}$ are far below the 1.8 tons of $\mathrm{CO}_{2}$ per capita (which is sometimes seen as the global sustainability level), it is not justifiable to require that the developing countries cannot increase their level of emissions.

The question of relative and absolute sustainability is important for the SuWi and ASA doughnut economy analyses. In this article, we used relative sustainability as the starting point. This means that we analyze whether the development is taking place in a more sustainable direction. The SuWi approach can also be used for analyzing absolute sustainability. In that case, the absolute level of sustainability should be determined quantitatively. In many cases, this is very difficult. It cannot be determined what is the quantitative level of, for instance, sustainable biodiversity. The same applies also to social sustainability. In most cases, it is not possible to determine what the quantitative sustainable level of education or health is. That is the main reason why relative sustainability has been used in this analysis even though the method itself is suitable for analyzing absolute sustainability.

The SuWi approach is well suited for comparative analyses. With the results of the SuWi analysis and the ASA doughnut model, it is easy to compare the development of different countries and see where the most important areas of development are in each case. The visual presentation of the SuWi approach in the form of a doughnut provides a tool for easy comparison and targeting policy actions. With a large list of sustainable 
development goals, it is important to easily get an overview of the most critical areas where improvement and policy actions are needed.

The selection of the variables and indicators for the analysis is crucial. In this analysis, we mainly used the SSI database for the indicators because it provides quite a comprehensive and reliable source of data. The problem with the SSI database is that it has not been updated recently and the latest update seems to have some discontinuities in the time series. The availability of time series data in the analysis gives possibilities for trend analysis and the estimation of possible future development paths. For the comparative scientific analysis, it is crucial to have a reliable database where similar criteria for data collection and analysis for different countries can be trusted. Otherwise, the data problems can lead to biased estimates of the development processes. The UN SDG database should provide a reliable data source for this type of comparative analysis, but the coverage of the database should be improved to cover all the countries in the world with as many variables as possible.

The SuWi approach can be used not only for national level analysis but also for the analysis of sub-national development or groups of countries (such as the EU). The municipal or provincial level analysis could provide important information for local-level policy planning, but very often the data availability is the main problem.

The SuWi approach provides a flexible tool for sustainability analysis. It can be used at different levels of analysis (regional, national, global) and for analyzing different aspects of sustainability (weak, strong) as well as different fields of development (different aspects of social and environmental development). Only the availability of suitable quantitative indicators restricts its area of use. A systematic analysis of the social-environmentaleconomic interactions using the developed tool can shed light on the complex interactions of the development in the different dimensions and can steer the policy measures to critical and most effective areas requiring development efforts.

The developed SuWi approach and ASA doughnut can provide valuable information for policy planning. This requires that the results of the research be easily communicated and the visualization of the results is crucial in this respect. The visualization of the dynamic behavior of societies in relation to sustainability is one of the main challenges. The visualization of the dynamic changes in sustainability with the developed tools is possible, but it requires additional development work. One area of future development is also to make the tools so easy to use that all planners can easily include them in their toolbox and use them in their daily activities. This is also related to database development where easy access to reliable data is crucial.

The doughnut economy approach by Raworth is an illustrative description of the general sustainability basis developed in the Brundtland Commission. The methodology developed in this article based on advanced sustainability analysis (ASA) and the derived sustainability window (SuWi) method provides a tool for quantification of the doughnut economy. The ASA doughnut method with its holistic scope and visual simplicity, coupled with its scientific grounding, provides a solid basis for analyzing sustainable development and for future policy planning and action.

Author Contributions: J.L. Conceptualization, J.L., J.V. and J.K.-o.; methodology, J.L. and J.V.; software, J.L.; validation, J.L.; formal analysis, J.L.; investigation, J.L., J.V. and J.K.-o.; resources, J.L., J.V.; data curation, J.L.; writing-original draft preparation, J.L., J.V. and J.K.-o.; writing-review and editing, J.L., J.V. and J.K.-o.; visualization, J.L.; supervision, project administration and funding acquisition J.L., J.V. and J.K.-o. All authors have read and agreed to the published version of the manuscript.

Funding: This research was funded by The Academy of Finland, grant number 320229.

Institutional Review Board Statement: Not applicable.

Informed Consent Statement: Not applicable. 
Data Availability Statement: Publicly available datasets were analyzed in this study. This data can be found here: http:/ / wikiprogress.org/data/dataset/datatables; https: / / www.iea.org/subscribeto-data-services/co2-emissions-statistics; http:/ / hdr.undp.org/en/data, (Accessed on 18 June 2020).

Conflicts of Interest: The authors declare no conflict of interest.

$\begin{array}{ll}\text { Abbreviations } \\ \text { List of acronyms } \\ \text { Acronym } & \text { Explanation } \\ \text { ASA } & \text { Advanced Sustainability Analysis } \\ \text { ASEAN } & \text { The Association of Southeast Asian Nations } \\ \mathrm{CO}_{2} & \text { Carbon dioxide } \\ \mathrm{CO}_{2 \text { eq }} & \text { Carbon dioxide equivalent } \\ \text { EU } & \text { European Union } \\ \text { GDP } & \text { Gross Domestic Product } \\ \text { GDP } & \text { Minimum Gross Domestic Product } \\ \text { GDP } & \text { Maximum Gross Domestic Product } \\ \text { GDP } & \text { Real Gross Domestic Product } \\ \text { GDP } & \text { Maximum Gross Domestic Product in strong sustainability } \\ \text { GDP } & \text { Maximum Gross Domestic Product in weak sustainability } \\ \text { GHGs } & \text { Greenhouse gases } \\ \text { GPI } & \text { Genuine Progress Indicator } \\ \text { HDI } & \text { Human Development Index } \\ \text { IEA } & \text { International Energy Agency } \\ \text { ISEW } & \text { Index of Sustainable Economic Welfare } \\ \text { OECD } & \text { Organisation for Economic Co-operation and Development } \\ \text { RCEP } & \text { The Regional Comprehensive Economic Partnership } \\ \text { SDG } & \text { Sustainable Development Goal } \\ \text { SDI } & \text { Sustainable Development Indicator } \\ \text { SSI } & \text { Sustainable Society Index } \\ \text { SuWi } & \text { Sustainability Window } \\ \text { UN } & \text { United Nations } \\ \text { UNDP } & \text { United Nations Development Programme } \\ \text { WCED } & \text { World Commission on Environment and Development } \\ & \end{array}$

\section{References}

1. UN. Secretary-General. Commission on Environment. In Report of the World Commission on Environment and Development: Our Common Future; Oxford University Press: Oxford, UK, 1987.

2. Repetto, R.; Magrath, B.W. Natural Resources Accounting; World Resources Institute: Washington, DC, USA, 1988.

3. Hamilton, K. Green adjustments to GDP. Resour. Policy 1994, 20, 155-168. [CrossRef]

4. Hoff, J.V.; Rasmussen, M.M.; Sørensen, P.B. Barriers and opportunities in developing and implementing a Green GDP. Ecol. Econ. 2020, 181, 106905. [CrossRef]

5. Daly, H.E.; Cobb, C. (Eds.) For the Common Good; Beacon Press: Boston, MA, USA, 1989; pp. 401-455.

6. Brennan, A.J. Theoretical foundations of sustainable economic welfare indicators-ISEW and political economy of the disembedded system. Ecol. Econ. 2008, 67, 1-19. [CrossRef]

7. Cobb, C.; Halstead, T.; Rowe, J. The Genuine Progress Indicator: Summary of Data and Methodology; Redefining Progress: San Francisco, CA, USA, 1995.

8. Kubiszewski, I. The Genuine Progress Indicator: A Measure of Net Economic Welfare. In Encyclopedia of Ecology; Elsevier: Amsterdam, The Netherlands, 2018; pp. 327-335.

9. Hoffren, J. Progress in welfare measurements and it's political usefulness. In Proceedings of the 13th International Conference of the European Society for Ecological Economics (ESEE 2019), Turku, Finland, 18-21 June 2019.

10. Kwatra, S.; Kumar, A.; Sharma, P. A critical review of studies related to construction and computation of Sustainable Development Indices. Ecol. Indic. 2020, 112, 106061. [CrossRef]

11. McGillivray, M. The human development index: Yet another redundant composite development indicator? World Dev. 1990, 19, 1461-1468. [CrossRef]

12. Sagar, A.D.; Najam, A. The human development index: A critical review. Ecol. Econ. 1998, 25, 249-264. [CrossRef]

13. Rees, W.E. Ecological footprints and appropriated carrying capacity: What urban economics leaves out. Environ. Urban. 1992, 4, 121-130. [CrossRef] 
14. Wackernagel, M.; Rees, W.E. Our Ecological Footprint: Reducing Human Impact on the Earth; New Society Publishers: Gabriola, BC, Canada, 1996.

15. Van De Kerk, G.; Manuel, A.R. A comprehensive index for a sustainable society: The SSI-the Sustainable Society Index. Ecol. Econ. 2008, 66, 228-242. [CrossRef]

16. Holden, E.; Linnerud, K.; Banister, D. Sustainable development: Our Common Future revisited. Glob. Environ. Chang. 2014, 26, 130-139. [CrossRef]

17. Kovacic, Z.; Giampietro, M. Beyond "beyond GDP indicators:" The need for reflexivity in science for governance. Ecol. Complex. 2015, 21, 53-61. [CrossRef]

18. United Nations. Indicators of Sustainable Development: Guidelines and Methodologies; United Nations: New York, NY, USA, 1996.

19. OECD. Measuring Sustainable Development; Organisation of Economic Co-Operation and Development: Paris, France, 2004.

20. Eurostat. Sustainable Development Goals and Indicators. Available online: https://ec.europa.eu/eurostat/web/sdi (accessed on 9 December 2020).

21. Rosenström, U. Sustainable Development Indicators: Much Wanted, Less Used? University of Helsinki: Helsinki, Finland, 2009.

22. United Nations. SDG Indicators-Metadata Repository. Available online: https://unstats.un.org/sdgs/metadata/ (accessed on 12 December 2020).

23. Raworth, K. A Safe and Just Space for Humanity: Can We Live within the Doughnut? Oxfam Discussion Papers. Available online: https: / / oi-files-d8-prod.s3.eu-west-2.amazonaws.com/s3fs-public/file_attachments/dp-a-safe-and-just-spacefor-humanity-130212-en_0_4.pdf (accessed on 14 November 2020).

24. Raworth, K. Doughnut Economics: Seven Ways to Think Like a 21st-Century Economist; Random House Business Books: London, UK, 2017.

25. Domazet, T.; Rilović, M.; Ančić, A.; Andersen, B.; Richardson, B.; Brajdić Vuković, L.; Pungas, M.; Medak, L. Encyclopedia of the World's Biomes, 1st ed.; Elsevier: Amsterdam, The Netherlands, 2020; pp. 276-286.

26. Rockström, J.; Steffen, W.; Noone, K.; Persson, Å.; Chapin, F.S.; Lambin, E.F.; Lenton, T.M.; Scheffer, M.; Folke, C.; Schellnhuber, H.J.; et al. A safe operating space for humanity. Nature 2009, 461, 472-475. [CrossRef]

27. Meadows, D.H.; Meadows, D.L.; Randers, J.; Behrens, W.W., III. The Limits to Growth. A Report for the Club of Rome's Project on the Predicament of Mankind; Universe Books: New York, NY, USA, 1972.

28. Daly, H.E. Steady-State Economics, 2nd ed.; Island Press: Washington, DC, USA, 1991.

29. Le Blanc, D. Towards Integration at Last? The Sustainable Development Goals as a Network of Targets. Sustain. Dev. 2015, 23, 176-187. [CrossRef]

30. Mainali, B.; Luukkanen, J.; Silveira, S.; Kaivo-Oja, J. Evaluating Synergies and Trade-Offs among Sustainable Development Goals (SDGs): Explorative Analyses of Development Paths in South Asia and Sub-Saharan Africa. Sustainability 2018, 10, 815. [CrossRef]

31. Malaska, P.; Kaivo-oja, J.; Luukkanen, J. A New Sustainability Evaluation Framework and Alternative Analytical Scenarios of National Economies. In Proceedings of the ESEE 2000, Transitions Towards a Sustainable Europe, Ecology-Economy-Policy, European Society for Ecological Economics, Vienna, Austria, 3-6 May 2000.

32. Kaivo-oja, J.; Luukkanen, J.; Malaska, P. Advanced sustainability analysis. In Our Fragile World, Challenges and Opportunities for Sustainable Development, Encyclopedia of Life Support, Systems and Sustainable Development; Tolba, M.K., Ed.; EOLSS Publishers Co. Ltd.: Oxford, UK, 2001; Volume 2.

33. Kaivo-Oja, J.; Luukkanen, J.; Malaska, P. Sustainability Evaluation Frameworks and Alternative Analytical Scenarios of National Economies. Popul. Environ. 2001, 23, 193-215. [CrossRef]

34. Vehmas, J.; Malaska, P.; Luukkanen, J.; Kaivo-oja, J.; Hietanen, O.; Vinnari, M.; Ilvonen, J. Europe in the Global Battle of Sustainability: Rebound Strikes Back? Advanced Sustainability Analysis; Turku School of Economics and Business Administration: Turku, Finland, 2003.

35. Vehmas, J.; Luukkanen, J.; Kaivo-Oja, J. Linking analyses and environmental Kuznets curves for aggregated material flows in the EU. J. Clean. Prod. 2007, 15, 1662-1673. [CrossRef]

36. Kaivo-Oja, J.; Panula-Ontto, J.; Vehmas, J.; Luukkanen, J. Relationships of the dimensions of sustainability as measured by the sustainable society index framework. Int. J. Sustain. Dev. World Ecol. 2014, 21, 39-45. [CrossRef]

37. Luukkanen, J. Sustainability Window Analysis (SuWi). Sustainability of Chinese Development in Relation to Poverty-Environment Nexus. Paper presented in CHEC Seminar, Tampere, Finland 2013. Available online: https://www.researchgate.net/publication/ 342751026_Sustainability_Window_Analysis_SuWi_Sustainability_of_Chinese_development_poverty_environment_nexus (accessed on 14 January 2021).

38. Luukkanen, J.; Kaivo-oja, J.; Vehmas, J.; Panula-Ontto, J.; Häyhä, L. Dynamic Sustainability. Sustainability Window Analysis of Chinese Poverty-Environment Nexus Development. Sustainability 2015, 7, 14488-14500. [CrossRef]

39. Luukkanen, J.; Kaivo-Oja, J.; Vähäkari, N.; O’Mahony, T.; Korkeakoski, M.; Panula-Ontto, J.; Phonhalath, K.; Nanthavong, K.; Reincke, K.; Vehmas, J.; et al. Green economic development in Lao PDR: A sustainability window analysis of Green Growth Productivity and the Efficiency Gap. J. Clean. Prod. 2019, 211, 818-829. [CrossRef]

40. Sustainable Society Index (SSI), Data and Resources. Available online: http://wikiprogress.org/data/dataset/datatables (accessed on 15 November 2020).

41. IEA. CO2 Emissions Statistics, International Energy Agency 2020. Available online: https://www.iea.org/subscribe-to-dataservices / co2-emissions-statistics (accessed on 18 June 2020). 
42. UNDP. Human Development Reports. Available online: http://hdr.undp.org/en/data (accessed on 15 November 2020).

43. Perangin-Angin, R.; Sulistiono; Kurnia, R.; Fahrudin, A.; Suman, A. Fishery sustainability study with sustainability window (SuWi) analysis in the South China Sea (Indonesia Fisheries Management Area 711). IOP Conf. Ser. Earth Environ. Sci. 2018, 176, 012036. [CrossRef]

44. Rumagia, F.; Boer, M.; Kurnia, R.; Kamal, M.M. Sustainability Window Approach for Fisheries Management at the Coastal Area of Ternate Island, North Maluku Province. Indones. J. Urban Environ. Technol. 2020, 3, 136-148. [CrossRef]

45. ADB. Country View-Key Indicators Database-Asian Development Bank 2020. Available online: https:// kidb.adb.org/kidb/ sdbsCountryView / countryViewResult?selectedCountryId=200 (accessed on 7 January 2021).

46. ADB. Special Topic: The Impact of the Coronavirus Outbreak-An Update. In Asian Development Outlook What Drives Innovation in Asia? The Asian Development Bank: Manila, Philippines, 2020.

47. Schneider, F. The Size of the Shadow Economies of 145 Countries all over the World: First Results over the Period 1999 to 2003. IZA Discuss. Pap. 2004, 1431, 64. 